\title{
FRAGILIDADES, FORTALEZAS E DESAFIOS NA FORMAÇÃO DO ENFERMEIRO
}

\author{
Weaknesses, strengths and challenges in the nurse's education \\ Debilidades, fortalezas y desafíos en la formación del enfermero
}

Jamila Geri Tomaschewski Barlem

Simoní Saraiva Bordignon ${ }^{4}$
Valéria Lerch Lunardi²

Caroline Ceolin Zacarias ${ }^{5}$
Edison Luiz Devos Barlem ${ }^{3}$

Wilson Danilo Lunardi Filho ${ }^{6}$

\section{RESUMO}

Pesquisa qualitativa que objetivou identificar a percepção do enfermeiro quanto ao seu preparo profissional, a partir da formação conferida pela graduação, e identificar aspectos da formação que contribuem para o enfrentamento dos conflitos e dilemas do cotidiano de trabalho. Os dados foram coletados entre agosto e dezembro de 2009, com oito enfermeiras de um hospital público federal do extremo sul do Brasil, por meio de entrevistas semiestruturadas. Utilizou-se a análise temática no tratamento dos dados, emergindo duas categorias: fragilidades no processo formativo e fortalezas na formação profissional. Encontrar alternativas para melhor suprir as necessidades da prática profissional é um desafio que requer não só o conhecimento das lacunas deixadas pelo curso de graduação, mas, também, formas de consolidar as fortalezas existentes no processo de formação.

Palavras-chave: Enfermagem. Educação em Enfermagem. Pesquisa em avaliação de enfermagem. Ética

\begin{abstract}
This qualitative research aimed at identifying the nurses' perception of their professional training starting from the education provided by undergraduate studies, and identifying aspects in education which contribute for facing the conflicts and dilemmas of the work routine. Data was collected between August and December of 2009, from eight nurses of a public federal hospital in the far south of Brazil, through semi-structured interviews. Thematic analysis was used for data treatment, two emerging categories: weaknesses in the formative process, and strengths in the professional education. It has been realized that finding alternatives to better fulfill the needs of the professional practice is a challenge that requires not only knowledge of the gaps left by undergraduate studies, but also ways of consolidating the strengths present in the education process.
\end{abstract}

Keywords: Nursing. Nursing Education. Research on Nursing Evaluation. Ethics

\section{Resumen}

Se trata de una investigación cualitativa que tuvo como objetivo identificar la percepción del enfermero frente a su preparo profesional a cerca de la formación ofrecida por el curso e identificar los aspectos de la formación que contribuyen para el enfrentamiento de los conflictos y dilemas de la práctica diaria. Los datos fueron recogidos entre agosto y diciembre de 2009, con ocho enfermeros en un hospital público en el sur de Brasil, a través de entrevistas semiestructuradas. Se utilizó el análisis temático en el procesamiento de los datos, obteniéndose dos categorías: debilidades en el proceso formativo y fortalezas en la formación profesional. La búsqueda por alternativas para mejor satisfacer las necesidades de la práctica profesional es un desafío que requiere no sólo el conocimiento de los vacíos dejados por el curso, sino también la manera de consolidar las fortalezas existentes en el proceso de formación.

Palabras clave: Enfermería. Educación en Enfermería. Pesquisa en Evaluación de Enfermería. Ética.

\footnotetext{
${ }^{1}$ Mestre em Enfermagem. Doutoranda do Programa de Pós-Graduação em Enfermagem (PPGEnf) - Universidade Federal do Rio Grande (FURG). Bolsista CAPES/FAPERGS. Membro do Núcleo de Estudos e Pesquisas em Enfermagem e Saúde (NEPES) - FURG. Rio Grande-RS. Brasil. Email: jamila_tomaschewski@hotmail.com ; ${ }^{2}$ Doutora em Enfermagem. Docente do PPGEnf - FURG. Bolsista de Produtividade 1A em Pesquisa/CNPq. Líder do NEPES-FURG. Rio Grande- RS. Brasil. Email: vlunardi@terra.com.br ; ${ }^{3}$ Doutor em Enfermagem. Docente do PPGEnf - FURG. Pesquisador do NEPES-FURG. Rio Grande-RS. Brasil. Email: ebarlem@gmail.com ; ${ }^{4}$ Mestranda do PPGEnf - Universidade Federal de Pelotas (UFPel). Bolsista da Coordenação de Aperfeiçoamento de Pessoal de Nível Superior (CAPES). Membro do NEPES-FURG. Pelotas - RS. Brasil. Email: simoni_bordignon@yahoo.com.br; ${ }^{5}$ Mestre em Enfermagem. Membro do NEPES-FURG. Porto Alegre-RS. Brasil. Email: carol-enfermagem@hotmail.com; ${ }^{6}$ Doutor em Enfermagem. Docente do PPGEnf - FURG. Membro do NEPES-FURG.Rio Grande- RS. Brasil. Email: lunardifilho@terra.com.br
} 


\section{INTRODUÇÃO}

0 ensino de graduação em enfermagem vem sofrendo sucessivas mudanças curriculares, a partir de amplas discussões de novas propostas pedagógicas, no intuito de formar profissionais que atendam às necessidades do mercado de trabalho e de saúde da população, em uma perspectiva humanista ${ }^{1,2}$. Nesse sentido, espera-se que as instituiç̧ões de ensino estejam comprometidas com a formação de profissionais críticos, reflexivos, éticos e políticos, impulsionando a profissão e repercutindo positivamente na formação de enfermeiros com maior inserção e participação social'.

Para acompanhar as transformações decorrentes das constantes modificações no quadro político-social e econômico do Brasil, faz-se necessário que a Enfermagem, como profissão atuante nesse novo contexto social e de saúde, reorganize-se, com a finalidade de avançar não apenas na formação de um novo profissional, mas, principalmente, de um indivíduo crítico capaz de contribuir para a transformação do contexto em que está inserido ${ }^{3,4}$. No entanto, observa-se que ainda não se produziram mudanças no ensino que estejam suficientemente em consonância com as exigências do mercado de trabalho e que sejam capazes de preparar profissionais centrados no cuidado humanizado e contextualizado, bem como envolvidos na transformação da realidade ${ }^{5}$.

As sucessivas mudanças curriculares nos cursos de graduação em enfermagem, comumente, não são precedidas de uma análise da realidade profissional dos enfermeiros, assim como não têm sofrido avaliações acerca do seu impacto, uma vez que, na literatura, são encontrados poucos estudos de acompanhamento de egressos das universidades com o objetivo de identificar as fragilidades e fortalezas da formação, para que, desse modo, se possa refletir sobre alterações que ainda necessitam ser implementadas ${ }^{6}$.

Considera-se que o desafio para ocupação de espaços pela enfermagem está relacionado, principalmente, à formação de enfermeiros competentes tecnicamente no cuidado humano, éticos, políticos e comprometidos com o papel social da enfermagem ${ }^{7}$. Dessa maneira, a formação profissional que se pretende para os estudantes dos cursos de enfermagem deve ser fundamentada em conhecimentos e, principalmente, na ética, direcionada para a capacidade de identificar problemas, buscando alternativas para superálos, por meio do desenvolvimento do raciocínio crítico, da autonomia, da criatividade e da comunicação.

É de grande relevância que os profissionais reflitam quanto ao seu processo de formação, a partir de suas experiências e enfrentamentos no cotidiano de trabalho, confrontando as competências adquiridas e desenvolvidas no curso de graduação com a realidade profissional, sugerindo mudanças e contribuindo para uma formação capaz de atender as necessidades do exercício da profissão.
Assim, esse estudo justifica-se em virtude da necessidade de identificar as fragilidades e fortalezas do processo de formação profissional do enfermeiro e os aspectos da formação que contribuem para o enfrentamento dos conflitos e dilemas do cotidiano de trabalho, o que poderá auxiliar na construção de estratégias para qualificar a formação profissional do enfermeiro.

0 presente estudo teve como objetivos: identificar a percepção do enfermeiro quanto ao seu preparo profissional, a partir da formação conferida pela graduação; identificar aspectos da formação que contribuem para o enfrentamento dos conflitos e dilemas do cotidiano de trabalho.

\section{METODOLOGIA}

Trata-se de uma pesquisa qualitativa, do tipo exploratório-descritiva, a qual possibilita ao pesquisador uma aproximação maior com as experiências vivenciadas pelos sujeitos, envolvendo um universo de significados, crenças, valores e atitudes?.

A pesquisa foi desenvolvida em um hospital público federal do extremo sul do Brasil, com enfermeiros atuantes nessa instituição. Os critérios para a seleção dos sujeitos foram: ser enfermeiro, atuante no respectivo hospital; ter disponibilidade para responder ao instrumento de pesquisa; $\mathrm{e}$ ter concluído o curso de graduação nos últimos dez anos, por se entender que este período facilitaria a identificação das fortalezas e fragilidades da formação.

Foram respondentes do estudo oito enfermeiros, selecionados intencionalmente, por conveniência, realizandose a busca por informantes com as características apresentadas metodologicamente e privilegiando aqueles que tivessem os atributos que o pesquisador pretendia conhecer ${ }^{9}$.

A coleta de dados ocorreu no período de agosto a dezembro de 2009, por meio de entrevistas semiestruturadas, gravadas, com duração média de 50 minutos, contendo questões fechadas para a caracterização dos sujeitos, e as seguintes questões abertas, relacionadas à formação profissional e a como essa formação responde às necessidades da prática: Como você vê a sua formação na graduação? Você considera que o curso de graduação preparou para as necessidades da prática profissional? Quais as principais for talezas na sua formação? Quais as principais fragilidades na sua formação? Você enfrenta conflitos e dilemas no cotidiano de trabalho? Em caso positivo, como a sua formação na graduação contribuiu para o enfrentamento desses conflitos e dilemas?

0 processo de análise dos dados realizou-se por meio de análise temática, a partir dos objetivos propostos, com préanálise, exploração e codificação, análise e interpretação ${ }^{9}$. A análise temática consiste na busca pelos núcleos de sentido no texto analisado, cuja presença ou frequência apresentem significado e relevância para o objetivo visado?.

Os preceitos éticos foram obedecidos em sua totalidade. Submeteu-se o projeto de pesquisa ao Comitê de Ética em 
Pesquisa na Área da Saúde da Universidade Federal do Rio Grande - CEPAS/FURG, sendo aprovado (PARECER N. 69/ 2009). Para garantir o anonimato, os sujeitos foram identificados pela letra $\mathrm{E}$, seguida pelo número correspondente à ordem de realização da entrevista, de E1 a E8, acrescido de $\mathrm{U} 1$ ou U2, de acordo com a universidade de origem do curso de graduação

\section{RESULTADOS E DISCUSSÃO}

A caracterização dos sujeitos foi realizada a partir da análise das questões fechadas. Os oito informantes eram do sexo feminino, todas enfermeiras concursadas, com idade entre 26 e 45 anos, graduadas por universidades federais do extremo sul do País; seis enfermeiras obtiveram sua formação na universidade U1 e duas, na universidade U2. Atuavam em diferentes unidades, dentre as quais: unidade de clínica médica, pediatria, centro obstétrico, maternidade e comissão de controle de infecção hospitalar (CCIH). 0 tempo de trabalho variou de dois a nove anos, com média de 5,06 anos.

A partir da análise temática dos dados obtidos com as respostas às questões abertas, construíram-se duas categorias: fragilidades do processo formativo e for talezas na formação profissional, apresentadas a seguir.

\section{Fragilidades do processo formativo}

Mediante a análise das falas dos sujeitos entrevistados, perceberam-se algumas lacunas no processo formativo, principalmente relacionadas ao exercício de uma prática predominantemente generalista, em uma determinada área de especialidade, em detrimento das outras.

Foi mais visado, em toda graduação, o cuidado ao adulto. Os professores falavam mais no adulto. $E$ eu sentia necessidade pra trabalhar com criança. (E1U1)

A graduação prepara muito mais e direciona muito mais para o adulto. (E2U2)

Eu acho que, na verdade, a noção geral tu consegues ver bem. Faltam coisas mais específicas. Pediatria foi uma grande fragilidade na minha graduação. Área de bloco cirúrgico foi bem complicado. (E4U2)

Assim como constatado por outro estudo, na percepção de egressos prevalece a necessidade de vivenciar experiências em unidades especializadas, fundamental para a formação profissional do enfermeiro ${ }^{7}$. Dessa forma, evidencia-se um desafio, havendo a necessidade de formar profissionais generalistas, considerando as questões políticas e econômicas, mas, também, atendendo às diversas especializações que emergem no âmbito da saúde? .

A realização de atividades práticas não próximas das funções desenvolvidas pelos enfermeiros das diferentes unidades é uma situação comumente adotada nas aulas práticas das disciplinas de alguns cursos de enfermagem, contribuindo para o distanciamento do estudante da dinâmica própria da unidade de trabalho nas instituições de saúde, reforçando a dicotomia entre teoria e prática. Verifica-se, assim, que:

O cenário de um hospital universitário é um cenário idealizador. A gente tenta se aproximar o mais possível do livro. Quando tu vais para uma instituição privada, a conversa é outra [...] (E1U1)

É muito diferente o que a gente vê durante nossos estágios e o que a gente vê enquanto trabalha [...] (E3U1)

Às vezes, acontecem outras situações mais interessantes que a gente não presencia, porque não foi o momento, não aconteceu aquilo ali, ou já tinha sido resolvida aquela situação. (E1U1)

À semelhança de nossos achados, foi identificado que ainda existem "contradições entre a formação teórico-prática e a práxis profissional", o que representa um desafio para formação profissional do enfermeiro ${ }^{7: 559}$. Nessa perspectiva, faz-se necessário que estratégias pedagógicas, especialmente metodologias ativas, sejam mais bem exploradas no processo formativo do enfermeiro, contribuindo para aproximar a formação e a prática profissional ${ }^{7}$.

Quanto mais se aproximar teoria e prática, melhor vai ser a formação. Temos que visualizar aquilo que vimos na sala de aula. Discutir, aproximar, contextualizar e problematizar as situações que são vivenciadas, dentro da formação do profissional. (E6U1)

Apesar de os conteúdos abordados em sala de aula e nas aulas práticas favorecerem o desenvolvimento das habilidades e aptidões técnicas necessárias para o exercício profissional, são os conflitos e dilemas éticos que parecem exigir mais do profissional, necessitando que desenvolva sua capacidade de raciocínio crítico e tomada de decisão, buscando alternativas que favoreçam o cliente, a própria equipe profissional e a instituição.

A técnica, a habilidade, ela é importante, mas a gente aprende fazendo algumas vezes e, se tu não aprenderes a pensar, tu só sais repetindo. [...] Aprender a pensaréo mais importante. A capacidade de pensar, de questionar, de cogitar estratégias de enfrentamento para os problemas, isso é o mais importante (E6U1) 


\section{Fragilidade, fortalezas e desafios na formação do Enfermeiro}

Esses conflitos apenas são vivenciados quando as aulas práticas e estágios aproximam-se da dinâmica das unidades. Tal situação nem sempre é alcançada, o que é manifestado nas falas dos sujeitos entrevistados, evidenciando-se que a "formação deve ser pautada no contexto da realidade e não centrada em conteúdos descontextualizados dos aspectos sócio, político, econômico e cultural em que a sociedade se organiza"10:674.

Os conflitos [...] eles [os docentes] não mostram como são. Isso eles não dizem pra gente. Acompanhar mais a realidade iria ajudar a enxergar esses conflitos. (E2U2)

No trabalho da enfermagem, percebe-se que o modo como os conflitos éticos são enfrentados pode ser decorrente de uma formação acadêmica que não distingue os problemas cotidianos como situações que necessitam ser discutidas, problematizadas e repensadas, o que pode comprometer a formação ética dos sujeitos envolvidos ${ }^{11}$.

A inabilidade técnica, em momento algum, foi enfatizada pelos entrevistados como uma fragilidade vivenciada, confirmando que a destreza manual é desenvolvida com o cotidiano de trabalho. A falta de habilidade no relacionamento pessoal, no entanto, apresenta-se, segundo os entrevistados, como uma das suas maiores fragilidades no exercício profissional, uma vez que não parece haver suficiente investimento na formação dos futuros enfermeiros para interagirem com outros sujeitos com origens, interesses, conhecimentos, culturas e papéis diferentes.

Quando eu comecei a trabalhar, eu vi que era a coisa que menos a gente sabe quando sai da faculdade, que é a questão das relações interpessoais. É o que tem de mais difíicil. Em nenhum momento, na minha graduação, se falou $e$ se discutiu essa questão de relação interpessoal, porque o que acontece, quando se vem pra campo de estágio, é que se vem com aquela visão de que a gente tem que aprender, tem que pegar os procedimentos. [...] a gente não se dá conta que não vai sair formada com a prática. A prática a gente tem no dia a dia. 0 que a gente precisa é pensar nas relações interpessoais e não querer ter apenas uma prática para saber passar uma sonda em cinco minutos. (E3U1)

Entende-se, assim, que a formação profissional do enfermeiro ultrapassa as habilidades para a execução de técnicas e procedimentos, perpassando o desenvolvimento do conhecimento, da diversidade de experiências vivenciadas e da ética, o que contribuirá para a construção e consolidação da vida profissional ${ }^{7}$.
A capacidade de comunicar-se adequadamente e de mediar relações é característica determinante de um profissional enfermeiro qualificado, especialmente por relacionar-se proximamente com múltiplos sujeitos. 0 "saber relacionar-se com os pacientes é um dos principais atributos de um bom enfermeiro", assim como são de fundamental importância os relacionamentos com a equipe multiprofissional:559.

Também foram apontadas, ao longo das entrevistas, suas dificuldades em realizar mudanças nas unidades de trabalho, em desenvolver projetos que visem à melhoria na assistência ou mesmo em dialogar com as chefias. Materiais em quantidade insuficiente ou mesmo inexistentes, número reduzido de funcionários, implicando sobrecarga para as equipes e outras situações cotidianas podem potencializar as dificuldades já vivenciadas em resolver os conflitos da equipe de enfermagem, na elaboração de escalas diárias ou de férias, em divergências com outros profissionais da área da saúde, ou mesmo com os serviços de apoio.

Mostrar, também, para os alunos não só a parte bonita da assistência, mas mostrar para eles a falta de materiais, que faltam funcionários e que falta todo um suporte que, muitas vezes, a gente precisa. (E1U1)

Nos estágios, a gente não improvisava. [...] Tanto que a maioria dizia que na realidade era diferente. [...] Nem sempre tu vais fazer um curativo com um pacote de curativo. Mas, no estágio, a gente sempre fez com pacote de curativo. (E8U1)

Tu confeccionas a escala na aula, mas tu não sabes todos os conflitos que tu vais ter pra confeccionar aquela escala. Às vezes, tu passas por unidades calmas no estágio ou tem alguns professores que preferem até não pegar alguns tipos de intercorrências, pra não atrapalhar aquela rotina no estágio. (E2U2)

Quando fui trabalhar, não tinha nada daquilo que a gente imagina ter. Não tinha recursos e tinha toda uma burocracia que a gente não tinha visto. (E7U1)

Essas situações intensificam-se quando o campo de prática não é o hospital universitário, local que geralmente abriga as práticas de ensino e prioriza um modelo de assistência de enfermagem, visando e proporcionando condições essenciais ao processo de formação do profissional enfermeiro, o que diverge da realidade atual de grande parte das instituições de saúde ${ }^{12}$.

A existência de docentes afastados da assistência ou sem a suficiente experiência profissional é citada como fonte de fragilidades no processo de formação, uma vez que 0 
distanciamento da prática assistencial dificulta ainda mais o exercício de um ensino mais próximo da realidade e, consequentemente, o enfrentamento de situações nem sempre abordadas nas aulas teóricas e práticas.

Nós temos professores que são muito teóricos e têm pouca prática. Então, a gente vem pra campo de estágio com professores que têm muita teoria e que são ótimos, mas que não têm a prática. Isso é uma falha da graduação. Os nossos professores não têm a parte clínica. Isso dificulta nossa formação. (E3U1)

Os professores, dentro da graduação, estão muito distantes da prática. Faz muito tempo que eles trabalharam na assistência. Então, isso dificulta muito pra gente, porque, quando eles estão dentro da sala de aula, é uma realidade, quando tu entras no hospital, é completamente diferente. (E4U2)

\section{Fortalezas na formação profissional}

No que se refere às potencialidades existentes no processo formativo, contraditoriamente, são enfatizadas a utilização do forte suporte teórico na construção do conhecimento nas diferentes disciplinas e a formulação de estratégias que contribuam para a superação das dificuldades enfrentadas ao longo da graduação.

A teoria a gente consegue vencer. Vemos tudo na teoria, sabemos o que temos que fazer e quando [...] (E8U1)

A gente precisa ter o conhecimento. Eu acho que isso é o fundamental na graduação, a questão de desenvolver o conhecimento, de refletir, de te formar um profissional crítico. [...] tu só conquistas alguma coisa, se tu tens conhecimento. Tu só vais poder discutir uma conduta que tu não achas ética, que tu não achas correta, se tu tiveres conhecimento. (E3U1)

"O embasamento teórico é considerado como sendo de fundamental importância para o início da atuação profissional" 8:559, uma vez que a teoria, mesmo que concebida pelos entrevistados como pouco aproveitada e mal direcionada no período formativo, serve de base para o enfrentamento das experiências futuras. Para que o estudante desenvolva condições de tomar decisões e adotar condutas mais adequadas, a capacidade de observar, avaliar e sistematizar deve ser parte de suas habilidades pessoais, potencializadas pelo suporte teórico oferecido na graduação.

Essas capacidades são apontadas como essenciais na formação dos estudantes, pois a observação direta das situações vivenciadas na prática constitui-se como elemento fundamental na construção de estratégias para os enfrentamentos do exercício profissional, "uma vez que é pela reflexão e teorização, a partir de situações da prática, que se estabelece o processo de ensino-aprendizagem"13:293.

Quando a gente está na graduação, com todo conhecimento, com tudo que é discutido dentro da sala de aula, das atividades práticas, a gente consegue visualizar muitas coisas, a gente percebe. Então, eu acho que a graduação, ela me ensinou a perceber e trouxe alguns valores da profissão. (E6U1)

Quando eu fazia estágio, eu via muitas questões. Eu ficava observando, porque não adianta, também, o professor ficar falando na aula aquela coisa toda sobre conscientização, diálogo, trabalhar em equipe [...] isso a gente ouve em qualquer lugar. Só que tu só vais sentir isso, por meio da observação. (E1U1)

Foi salientada a importância do interesse pessoal do estudante para suprir possíveis lacunas existentes no ensino, principalmente através da vivência extracurricular, de leituras e da participação em projetos de pesquisa e extensão. Por meio dessas estratégias, os entrevistados afirmaram ser possível desenvolver competências, visualizando, de forma mais integral e participativa, a realidade repleta de conflitos e contradições não abordados satisfatoriamente nas aulas teóricas, ou mesmo nas aulas práticas.

A gente é preparada, desde que a gente busque isso. Eu sempre busquei fazer estágio voluntário. (E3U1)

Acho que muito da formação depende da gente. Eu acho que tu não podes te contentar só como que tu vês na universidade. Eu fiz muito estágio voluntário. A gente tem que buscar. (E4U2)

Ainda, o interesse pessoal do estudante pode favorecer o exercício de mais autonomia nos processos de construção do conhecimento, "acarretando maior aproveitamento das práticas pedagógicas e, consequentemente, a formação de profissionais politizados e capacitados a atuar na construção da integralidade em favor da coletividade"14:12. A construção e a consolidação do conhecimento perpassam o ensino da teoria e da prática, no momento em que o estudante assume a responsabilidade da sua aprendizagem, através da interação com múltiplos sujeitos, da prática social e da vivência em realidades distintas ${ }^{7}$. 
O que me ajudou bastante na minha formação, dentro da graduação, foram os estágios voluntários [...] e foi essa questão, de estar voltado não só dentro da pesquisa pra articular com a prática, mas tentar alicerçar na minha formação a leitura. (E1U1)

Ao citarem os pontos positivos da graduação, enfatizaram a articulação entre ensino, pesquisa e extensão, integrando saberes e práticas que subsidiaram o crescimento dos entrevistados, principalmente dos estudantes que demonstravam maior interesse pessoal ao longo do curso. Nesse sentido, necessita-se investir na formação, no intuito de potencializar qualidades e problematizar as diferentes situações vivenciadas, estimulando o estudante a buscar e construir possibilidades de intervenção, a partir da integração entre 0 aprendizado acadêmico e a realidade profissional ${ }^{15}$.

Eu acho que a minha graduação foi uma graduação boa, porque eu desenvolvi pesquisa, que éuma coisa muito importante, eu desenvolvi extensão, eu desenvolvi a questão de prática. Sempre fiz estágio voluntário. Eu tentei aliar a pesquisa à assistência. (E3U1)

Ao propiciar ao estudante distintas formas de aprendizagem, em diferentes cenários de prática, proporcionam-se 0 aprimoramento e a consolidação do conhecimento adquirido, permitindo que se torne um sujeito ativo, capaz de promover mudanças e recriar saberes e práticas? Ainda, foi enfatizada pelos entrevistados a pesquisa como aspecto fundamental para a formação. Apontada como forma de construção e consolidação do conhecimento, a pesquisa articulada com o ensino e com a extensão possui o potencial de qualificar tanto os estudantes quanto o próprio curso, proporcionando subsídios e consistência para o desenvolvimento da sua autonomia no exercício das atividades como profissional ${ }^{8,16}$.

A universidade tem uma formação bem forte na questão da pesquisa, e isso é muito bom [...] porque a gente aprende a escrever, a gente aprende a pensar, a gente aprende a falar [...] (E6U1)

[...] faz com o que o curso em si se aprimore mais, busque novas formas de atualização, busque novas formas de fazer o cuidado. Isso é o objetivo maior da pesquisa. (E1U1)

Como constatado em um estudo que objetivou identificar a opinião dos graduandos de enfermagem sobre sua formação para o Sistema Único de Saúde, as atividades de pesquisa, durante a graduação, são imprescindíveis para o alcance de uma formação de qualidade, estimulando a criatividade, instrumentalizando e proporcionando subsídios na tomada de decisões'.

Entretanto, foi salientado pelos entrevistados que a ênfase somente na pesquisa pode acarretar um distanciamento das atividades desenvolvidas na assistência. $E$ ainda que a aproximação entre a pesquisa e a assistência poderá possibilitar a utilização do conhecimento, no intuito de qualificar e fundamentar a prática assistencial, fortalecendo, também, a enfermagem nas diferentes dimensões da profissão.

É um erro muito grande só pesquisar ou só fazer assistência. Na prática, ser só enfermeira assistencial, simplesmente, fazer o teu papel e ir embora, isso é muito ruim. (E3U1)

Acho interessante a pesquisa contínua. Só que, também, não se pode só focalizar a questão de pesquisa. Tem que trazer, também, a questão prática. Levar o aluno lá pra prática. Focalizar um pouco mais isso. (E1U1)

Por fim, destacou-se a contribuição trazida por alguns professores que atuavam, simultaneamente, na assistência e docência, demonstrando, de forma mais real e concreta, o que a prática assistencial iria exigir do profissional, assim como quais seriam as principais atribuições a serem desenvolvidas pelo enfermeiro.

A gente aprende a fazer escala e a fazer um monte de coisas da administração. Eu fui ver isso, mas com um professor substituto, que era enfermeiro da unidade e me ensinou. Eu fui aprender com ele isso. (E1U1)

Essa experiência docente favoreceu a promoção de discussões e reflexões, oportunizando, assim, ao estudante, o desenvolvimento do pensamento crítico acerca das situações a serem vivenciadas ${ }^{17}$.

\section{CONCLUSÃO}

Possíveis lacunas na graduação parecem estar relacionadas à falta de preparo dos profissionais para responder algumas necessidades da prática, especialmente no que tange aos relacionamentos interpessoais e à resolução de conflitos. Deparar-se com realidades diferentes das vivenciadas, durante o processo formativo, traz aos profissionais dificuldades para o exercício da profissão, uma vez que os cenários ainda idealizadores dos hospitais universitários parecem não fornecer aos estudantes vivências de situações reais, em que dilemas, incertezas, conflitos pessoais e falta de recursos sejam enfrentados. 
Em contrapartida, o forte suporte teórico desenvolvido durante a graduação é apontado como subsídio para 0 profissional, auxiliando o enfermeiro nos momentos de indecisão ou de dificuldades cotidianas e nos processos de tomada de decisão. Para contribuir ainda mais nesse sentido, dois aspectos foram salientados como fundamentais: um relacionado à observação das situações vivenciadas nas aulas práticas e estágios, e outro ao interesse pessoal do estudante. Também foi enfatizada a experiência de alguns professores que promoviam momentos de discussão e reflexão, durante as aulas teóricas e práticas, principalmente quando atuavam, simultaneamente, na docência e na prática assistencial.

Por fim, a pesquisa foi apontada como o fator articulador entre os múltiplos saberes do universo acadêmico, servindo de ponte entre extensão e ensino, além de promover o crescimento e desenvolvimento pessoal e profissional. Nesse sentido, encontrar alternativas para melhor suprir as necessidades da prática profissional é um desafio que requer não só o conhecimento das lacunas deixadas pelo curso de graduação, mas, também, modos de consolidar as fortalezas existentes no processo de formação.

0 estudo apresenta as limitações de uma pesquisa qualitativa, a qual não pretende generalizações. Ainda, em virtude do baixo número de trabalhos relacionados à formação do enfermeiro, é apontada a necessidade de novas pesquisas que auxiliem no processo de conhecimento das fragilidades e fortalezas da formação profissional, melhor direcionando o ensino de graduação em enfermagem brasileiro, contribuindo com o fortalecimento da profissão.

\section{REFERÊNCIAS}

1.Costa RKS, Miranda FAN. Opinião do graduando de enfermagem sobre a formação do enfermeiro para o SUS: uma análise da FAEN/UERN. Esc Anna Nery. 2010 mar; 14(1): 39-47.

2.Scherer ZAP, Scherer EA, Carvalho AMP. Reflexões sobre o ensino da enfermagem e os primeiros contatos do aluno com a profissão.Rev Latino-Am Enfermagem. 2006 mar-abr; 14(2): 285-91.

3.Faustino RLH, Egry EY. A formação da enfermeira na perspectiva da educação: reflexões e desafios para o futuro. Rev Esc Enferm USP. 2003; 36 (4): 332-37.

4.Brito AMR, Brito MJM, Silva PAB. Perfil sociodemográfico de discentes de enfermagem de instituições de ensino superior de Belo Horizonte. Esc Anna Nery. 2009 abr-jun; 13(2): 328-33.

5.Souza ACC, Filha MJMM, Silva LF, Monteiro ARM, Fialho AVM. Formação do enfermeiro para o cuidado: reflexões da prática profissional. Rev Bras Enferm. 2006 nov-dez; 59(6): 805-07.
6.Gabrielli JMW. Formação do enfermeiro: buracos negros e pontos luz [tese de doutorado]. Ribeirão Preto: Escola de Enfermagem/USP; 2004.

7.Corbellini VL, Santos BRL, Ojeda BS, Gerhart LM, Eidt OR, Stein SC et al . Nexos e desafios na formação profissional do enfermeiro. Rev Bras Enferm. 2010 ago; 63(4): 555-60.

8.Meira MDD, Kurcgant P.Avaliação da formação de enfermeiros segundo a percepção de egressos. Acta Paul Enferm. 2008; 21(4): 556-61.

9.Minayo MCS. 0 desafio do conhecimento: pesquisa qualitativa em saúde. $12^{\mathrm{a}}$ ed. São Paulo: Hucitec; 2010.

10.Meira MDD, Kurcgant P. 0 ensino de administração na graduação: percepção de enfermeiros egressos. Texto\&Contexto Enferm. 2009 dez; 18(4): 670-79.

11.Bordignon SS, Lunardi VL, Dalmolin GL, Tomaschewski JG, Lunardi Filho WD, Barlem ELD et al. Questões éticas do cotidiano profissional e a formação do enfermeiro. Rev Enferm UERJ. 2011 jan-mar; 19(1): 94-9.

12.Andrade JS, Vieira MJ. Prática assistencial de enfermagem: problemas, perspectivas e necessidade de sistematização. Rev Bras Enferm. 2005 jun; 58 (3): 261-65.

13.Erdmann AL, Rodrigues ACRL, Koerich MS, Backes DS, Drago LC, Klock P. 0 olhar dos estudantes sobre sua formação profissional para o Sistema Único de Saúde. Acta Paul Enferm. 2009 jun; 22 (3): 288-94.

14.Azevedo PS, Pereira WR. 0 discente como ali(en)ado no processo de formação em enfermagem. Societas. 2009 mar; 1(2): 7-14.

15.Backes DS, Erdmann AL. Formação do enfermeiro pelo olhar do empreendedorismo social. Rev Gauch. Enferm. 2009 jun; 30(2): 24248.

16.Erdmann AL, Leite JL, Nascimento KC, Lanzoni GMM. Vislumbrando o significado da iniciação científica a partir do graduando de enfermagem. Esc Anna Nery. 2010 mar; 14(1): 26-32.

17.De Biasi LS, Pedro ENR. Vivências de aprendizagem do cuidado na formaçã̃o da enfermeira. Rev Esc Enferm USP. 2009 set; 43(3): 506-11. 